El estrellato como mitología de la era digital: hiperculturalidad y El mal querer de... $\mid 388$

INNOVACIÓN TEÓRICA

\title{
El estrellato como mitología de la era digital: hiperculturalidad y El mal querer de Rosalía
}

Stardom as mythology of the digital age: hyperculturality and Rosalia's El mal querer

\author{
Estrelato como mitologia da era digital: \\ a hiperculturalidade e $\mathrm{El}$ mal querer de Rosalía
}

\author{
Mateu Terrasa Rico \\ Profesor Colaborador \\ (Universidad CEU San Pablo) \\ http://orcid.org/0000-0001-7788-3006 \\ España \\ Ignacio Blanco Alfonso \\ Catedrático \\ (Universidad CEU San Pablo) \\ https://orcid.org/0000-0002-2595-464X \\ España \\ Margarita Garbisu Buesa \\ Profesora titular \\ (Universidad a distancia de Madrid (UDIMA)) \\ https://orcid.org/0000-0003-2025-713X \\ España
}

Fecha de recepción: 10 de marzo de 2021

Fecha de revisión: 12 de marzo de 2021

Fecha de aceptación: 10 de mayo de 2021

Fecha de publicación: 1 de julio de 2021

Para citar este artículo: Terrasa Rico, M., Blanco Alfonso, I. y Garbisu Buesa, M. (2021).

El estrellato como mitología de la era digital: hiperculturalidad y El mal querer de Rosalía, Icono 14, 19(2), 388-410. doi: 10.7195/ri14.v19i2.1734 


\section{Resumen}

El estrellato constituye un ejemplo paradigmático de mitología contemporánea. A través de su función como receptáculos semiótico-culturales y somático-emocionales, las estrellas sirven como referentes y espejo del colectivo social que las engendra. En el seno de las comunidades digitales y a través de la tecnología interactiva, la liturgia de las celebrities, los rituales de los fans y la simbología de esta religión secular masiva alcanza su cénit. Nuestro primer objetivo es analizar el paralelismo entre el estrellato y la religión. Para ello, situaremos a los ídolos en un marco teórico y describiremos las transformaciones que las comunidades digitales de fans están experimentando. Nuestro segundo objetivo es interrelacionar el fenómeno transmedia del álbum El mal querer de Rosalía con la noción de "hiperculturalidad" propuesta por Byung-Chul Han. Expondremos cómo el universo conceptual generado por la artista catalana refleja las transformaciones a la que asisten las identidades en la cultura globalizada, hiperconectada y digital. El artículo concluye desarrollando la idea del estrellato como mitología moderna y la importancia de la tecnología digital interactiva en la transformación de los públicos en red. Así mismo, la difusión global e intergeneracional de la obra de Rosalía es sintomática del modelo no fundamentalista de la cultura globalizada, así como de la prominencia de lo tradicional, el consumo de lo estético-cultural y el papel activo de las audiencias en la configuración de la identidad cultural contemporánea.

Palabras clave: Música digital; Comunidades virtuales; Identidad cultural; Transmedia; Rosalía; Estrellato

\section{Abstract}

Stardom is a paradigmatic example of contemporary mythology. Through their function as semiotic-cultural and somatic-emotional receptacles, the stars serve as referents and mirror of the social collective that engenders them. Within digital communities and through interactive technology, celebrity liturgy, fan rituals, and the symbolism of this massive secular religion reach its zenith. Our first goal is to analyze the parallels between stardom and religion. To do this, we will place idols in a theoretical framework and describe the transformations that digital fan communities are undergoing. Our second objective is to interrelate the transmedia phenomenon of Rosalia's album El mal querer with the notion of "hyperculturality" proposed by Byung-Chul Han. We 
El estrellato como mitología de la era digital: hiperculturalidad y El mal querer de... | 390

INNOVACIÓN TEÓRICA

will expose how the conceptual universe generated by the Catalan artist reflects the transformations that identities attend in the globalized, hyper-connected and digital culture. The article concludes by developing the idea of stardom as modern mythology and the importance of interactive digital technology in the transformation of online audiences. Likewise, the global and intergenerational dissemination of Rosalia's work is symptomatic of the non-fundamentalist model of globalized culture, as well as the prominence of the traditional, the consumption of the aesthetic-cultural and the active role of audiences in the configuration of contemporary cultural identity.

Keywords: Digital music; Virtual Ccmmunities; Cultural identity; Transmedia; Rosalia; Stardom

\section{Resumo}

0 estrelato é um exemplo paradigmático da mitologia contemporânea. Por sua função de receptáculos semiótico-culturais e somático-emocionais, as estrelas servem como referentes e espelho do coletivo social que as engendra. Dentro das comunidades digitais e por meio de tecnologia interativa, liturgia de celebridades, rituais de fãs e o simbolismo dessa religião secular massiva atingem seu apogeu. Nosso primeiro objetivo é analisar o paralelismo entre estrelato e religião. Para isso, colocaremos os ídolos em uma estrutura teórica e descreveremos as transformações pelas quais as comunidades de fãs digitais estão passando. Nosso segundo objetivo é inter-relacionar o fenômeno transmídia do álbum mal querido de Rosalía com a noção de "hiperculturalidade" proposta por Byung-Chul Han. Vamos expor como o universo conceitual gerado pela artista catalã reflete as transformações que as identidades assistem no mundo globalizado, cultura hiperconectada e digital. 0 artigo conclui desenvolvendo a ideia do estrelato como mitologia moderna e a importância da tecnologia digital interativa na transformação do público online. Da mesma forma, a difusão global e intergeracional da obra de Rosalía é sintomática do modelo não fundamentalista da cultura globalizada, bem como da proeminência do tradicional, do consumo do estético-cultural e do papel ativo do público na configuração do contemporâneo. identidade cultural.

Palavras chave: Música digital; Comunidades virtuais; Identidade cultural; Transmídia; Rosalia; Estrelato 


\section{Introducción: estrellato y audiencias. Entre su fundamento académico y la cultura de masas}

Definimos el estrellato como un proceso por el cual un individuo es reconocido por sus cualidades o talento excepcional (Loy et al., 2018). En cambio, los términos "celebrity" y "fama igualitaria", a pesar de derivar del estrellato, hacen eco de una visibilidad más efímera y que no conlleva la necesidad de un logro especial más allá de la mera exposición mediática del individuo (Inglis, 2010; BusquetDuran, 2012; Turner, 2014). Podemos trazar la genealogía del estrellato en las figuras de los héroes míticos, los deportistas sobresalientes, los políticos, los actores de teatro y, a partir de 1930, los integrantes del star-system de Hollywood. Todos estos personajes públicos funcionan como modelos de conducta que suplen una necesidad afectivo-mítica del pueblo, esto es, "se erigen como espejos de los valores dominantes de un tiempo" (Busquet-Duran, 2012:13).

En el ámbito hispanohablante hallamos un vacío rotundo en torno a la investigación del estrellato y la cultura celebrity. Así mismo, el estudio del fenómeno de la cantante catalana Rosalía sigue inexplorado desde el ámbito científico. Este artículo pretende abrir el camino en ambas esferas, constituyendo una pionera aproximación teórica a un universo donde las únicas referencias, a caballo entre el ensayo y la obra divulgativa, son el libro El Trap. Filosofía millennial para la crisis en España (2019), del filósofo Ernesto Castro, y La Rosalía. Ensayos sobre el buen querer (Carrión, 2021), libro colaborativo editado por el crítico literario Jorge Carrión que aglutina una miríada de reflexiones en torno a los aspectos estéticos, poéticos y culturales del universo Rosalía.

Este vacío científico es sintomático de cómo, a pesar del innegable carácter polisémico y ramificado del estrellato como fenómeno social, aún hallamos una tendencia a la "desconfianza" en el entorno académico respecto al estudio de fenómenos eminentemente populares y masivos tales como el estrellato (Wolfheil et al., 2019). Desde la banal simulación de la realidad fijada por el concepto de sociedad del espectáculo (Debord, 1967), pasando por la crítica a la industria cultural y la cultura de masas de la Escuela de Frankfurt (Horkheimer \& Adorno, 1944/1998), nos encontramos con que el culto a las celebrities, tal y como Chris Rojek (2001: 51) observa, es 
El estrellato como mitología de la era digital: hiperculturalidad y El mal querer de... | 392

condenado por "esclavitud, falsa conciencia, 'obra del Diablo"' y es emparejado con "la trivialidad y superficialidad". De tal forma, la música mainstream y sus artistas se insertan en dinámicas que, en última instancia, son concebidas como una forma más del lenguaje despiadado del capitalismo, la globalización hegemónica y el mercantilismo (Illescas-Martínez, 2011; 2014), factores que, adicionalmente, se ven acentuados por la proliferación de internet como un no-lugar que aniquila la distancia y favorece las relaciones líquidas descritas por Zygmunt Bauman (Núñez Ladevéze \& Irisarri, 2015; Han, 2020). En la actualidad, teóricos como Byung-Chul Han señalan que "lo que predomina hoy es una comunicación sin comunidad" (Han, 2020: 11).

En esta misma línea, y siguiendo la estela crítica posestructuralista, podríamos considerar el estrellato y sus prácticas derivadas como una forma más de legitimación del capitalismo tecnológico y sus dinámicas de gubernamentalidad algorítmica (Rouvroy y Berns, 2015). Bajo esta visión, las economía del deseo de los individuos - concepto atribuido "a todas las formas de voluntad de vivir, de crear, de amar; a la voluntad de inventar otra sociedad, otra percepción del mundo, otros sistemas de valores" (Rolnik y Guattari, 2006: 255) - es reconducida a través de prácticas que retroalimentan y legitiman el funcionamiento de dicha teología política neoliberal. Esta dinámica circular, conocida como cibernética de segundo orden, es vista como "una condición necesaria para acabar con la alienación de la especie humana" (Foer, 2017: 24), donde diversas compañías como Apple, Facebook o Google siguen la estela de la cosmovisión de Silicon Valley y de uno de los padres fundadores de su idealismo tecnológico, Stewart Brand: "[La tecnología] ha creado los males del mundo. Solo la tecnología podía resolverlos" (Foer, 2017: 30).

De tal forma, prácticas aparentemente inocentes como la cosecha masiva de datos (big data), la personalización algorítmica, la promoción del yo en Instagram, Tik Tok y diversas plataformas de moda, o el fenómeno del estrellato como mitología contemporánea, constituirían ejemplos de la toxicidad del pharmakon ${ }^{1}$ o técnica: la desmoralización, automatización y proletarización de los valores sociales debido al uso teológico-político de la tecnología como propuesta de solución al malestar contemporáneo (Stiegler, 2015). Ficción política auto-perpetuada por un sistema de dominación cuasi invisible que propone narrativas tecnológico-utópicas en consonancia con la cosmovisión post-humanista y tecnocapitalista siliconiana (Sadin, 2018; Andrea Sereni, 2021). 


\section{INNOVACIÓN TEÓRICA}

No obstante, y asentada la relevancia de estos procesos teológico-políticos, no debemos quedarnos anclados únicamente en el escepticismo y pesimismo libertario propio de la mirada de corte posestructuralista (Eagleton, 2016), dado que dicha óptica puede tender a la polarización de las instituciones normativas como malévolas per se y su subversión como un valor siempre deseado y, por ello mismo, exento de toda toxicidad. Así mismo, considerar al capitalismo como un chivo expiatorio que, junto al desarrollo de la tecnología y las dinámicas neoliberales, constituye la eterna causa del malestar contemporáneo podría resultar en un análisis sociohistórico un tanto reduccionista de nuestro devenir cultural y del estrellato.

Integrando una postura más tecnófila que contemple la reapropiación de dicho pharmakon, el origen de la tecnología digital interactiva e internet ha sido asimilada como un potencial estímulo para el intercambio de información, la construcción de comunidades digitales y una ampliación de la vida democrática (Rheingold, 1996; Siles González, 2005). Las investigaciones recientes en el campo del estrellato reflejan cómo gracias a las redes sociales, los públicos congregados alrededor de los artistas muestran tendencias más activas en relación con la concienciación política, la implicación en el activismo y la creación de comunidades en base a una causa común (Jenkins, 2012; Jones, 2012; Click et al., 2015). Gracias al ecosistema digitalizado se desdibuja el binarismo entre productores de contenido y audiencias, hecho que cuestiona los preceptos de la teoría crítica sobre la pasividad de las audiencias a favor de actitudes más activas y comprometidas; este fenómeno se ve reflejado a través del concepto de "públicos en red" o "públicos conectados" (Ito, 2008: 11). Como resultado, se desintegra la relación imaginaria y unidireccional con las estrellas (p. ej.: la creación de romances imaginarios con actores de Hollywood) y pasamos a un plano que intensifica la intimidad con la estrella a través de la interacción con su "persona privada pública" desde las redes sociales (Marshall, 2010).

Desde esta visión, el estrellato podría habilitar prácticas que impliquen el intercambio de conocimiento, una mayor independencia respecto a los canales convencionales o de "masas", el fomento de la formación y el autodidactismo, la libre asociación y solidaridad comunitaria, el reconocimiento de las minorías, el empoderamiento colectivo, el cuidado mutuo y la hospitalidad hacia el otro. En definitiva, toda una miríada de espacios y rituales que permitan dirigir la economía del deseo hacía 
El estrellato como mitología de la era digital: hiperculturalidad y El mal querer de... | 394

una noción terapéutica del pharmakon. Pues, tal y como Adolfo Vera nos recuerda, la acepción helenística del concepto pharmakon puede hacer referencia tanto a "una cura que puede matar" como a un "veneno que puede curar" (Vera, 2020).

Ante esta encrucijada entre apocalípticos e integrados, como diría Umberto Eco (1984), debemos preguntarnos: ¿existe realmente una crisis de la comunidad? 0, acaso, ¿asistimos a una transformación de esta? La posición intermedia que en este artículo tratamos de explorar nos conduce a interrogarnos: ¿Es posible habitar el estrellato desde una posición crítica, autoconsciente y comprometida que genere espacios de reflexión, comunidad y trascendencia más allá del individualismo narcisista?

\section{Metodología}

La relevancia de nuestro objeto de estudio se fundamenta en su impacto cómo fenómeno de la era digital en nuestro país. Según los informes de Google Trends, Rosalía fue el personaje público más buscado por la población española en $2018^{2}$. Su aparición en la película Dolor y Gloria (2019) de Almodóvar o la gala de los premios Goya de 2019 confirman su consagración como hito mediático y cultural nacional. A nivel internacional, la promoción de El mal querer en Times Square y la obtención de un Grammy en 2020 y ocho Grammy Latino (dos en 2018, tres en 2019 y tres en 2020), nos hablan de su alcance global. El periódico The New York Times incluyó el single Malamente dentro de la lista internacional The 25 Songs That Matter Right Now mientras que la revista especializada Pitchfork otorgó a $\mathrm{Ma}$ lamente el puesto número 23 dentro de la lista The 200 Best Songs of the 2010s.

Mediante el estudio crítico del caso de Rosalía, nuestros objetivos son:

1. Ampliar el alcance teórico del estudio del estrellato en la era digital.

2. Definir el estrellato como mitología y religión contemporánea de la era digital.

3. Ahondar en los procesos identitarios que cataliza una figura contemporánea de gran alcance mediático y relevancia sociocultural como es la artista catalana.

Respecto al estudio del estrellato, situamos los celebrity studies como una de las "nuevas" disciplinas académicas surgidas a mediados del siglo XX que presenta 


\section{INNOVACIÓN TEÓRICA}

unos orígenes multidisciplinares (Marshall y Redmond, 2015), influenciados por los estudios culturales (Dyer, 1998), la sociología de los medios y el fenómeno fan (Morin, 1972; Jenkins, 2010; 2012), los estudios cinematográficos o el análisis de la música popular (Duffett, 2013; Loy et al., 2018), entre otros. Formando parte de un proyecto mayor de investigación, esta aproximación teórica de carácter exploratorio propone un enfoque en consonancia con dicho carácter transversal.

En la primera parte (epígrafes 3 y 4 ) llevamos a cabo un análisis crítico de las dinámicas de transformación a las que asiste la noción de comunidad y de fan aglutinados alrededor del estrellato. Realizaremos una síntesis bibliográfica de voces académicas que aporten un marco conceptual más allá de los "estereotipos desgastados" (Duffet, 2013: 301), escapando de la descripción de dichos fenómenos a través de conceptos reduccionistas como la pasividad o la mercantilización (Horkheimer y Adorno, 1944/1998; Illescas, 2011; 2014). Como recuerda Mark Duffett "el fenómeno fan ha sido moldeado por el legado de comentarios en torno a la cultura de masas y sus muchos críticos" (Duffet, 2013: 301). En el caso de este artículo, pretendemos reconciliar dicho legado junto a otras conceptualizaciones igualmente productivas que abren el campo de estudio a una concepción más individualizada, activa y dinámica de las audiencias en el seno de un mundo globalizado e hiperconectado (Ito, 2008; Jenkins, 2010; Jones, 2012).

En la segunda parte (epígrafe 5) revisaremos la noción de hiperculturalidad propuesta por Byung-Chul Han a través del estudio de caso de El mal querer de Rosalía. Este concepto clave nos permitirá describir los procesos a los que asiste la identidad cultural contemporánea en el marco de las sociedades digitalizadas. Este tipo de propuesta constituye una intersección teórica aún inexplorada, lo que revela el carácter novedoso de esta investigación exploratoria.

\section{Marco teórico}

Tras plantear una hipotética crisis de la comunidad, y en el marco del debate académico entre apocalípticos e integrados anteriormente mencionado, merece prestar atención al estrellato como proceso que aglutina sendas posturas enfrentadas: por un lado, constituye un fenómeno popular y masivo que se inserta en 
El estrellato como mitología de la era digital: hiperculturalidad y El mal querer de... | 396

un marco de producción estandarizado perteneciente al contexto de la industria cultural (Findeisen, 2015); por otro lado, se trata de un fenómeno de consumo posmasivo insertado en el espacio digital interactivo. Por lo tanto, el estrellato involucra necesariamente la recepción y cocreación de los ídolos por parte de una comunidad de prosumidores y fans. Es al integrar ambas ópticas que podemos determinar que las estrellas funcionan como:

1. Receptáculos semióticos que condensan significado cultural (Dyer, 1998). Estas conspicuas figuras reflejan los complejos procesos que transitamos como civilización en un contexto digital, global e hiperconectado: actitudes, narrativas, mitos, estereotipos, valores morales, arquetipos y frames culturalmente imbuidos (Terrasa Rico, 2021).

2. Receptáculos asemióticos y somáticos que canalizan afectos, emociones y vivencias personales (Redmond, 2015). Cuando "sentimos" cercana a una estrella que pone en palabras nuestros deseos, miedos y aspiraciones más profundos, establecemos un vínculo de intimidad o identificación -no recíproco- que nos acerca a la noción de "relaciones parasociales" (Rojek, 2001: 52). Es alrededor de las estrellas que son catalizados valores como el compañerismo, la solidaridad o la sensación de pertenencia al grupo.

De tal forma que, desde la función semiótico-cultural y somático-emocional, las estrellas aglutinan una miríada de acciones que, partiendo desde el nivel micro-social del individuo, impactan en la esfera pública y la acción política (Fiske, 1989). Sería reduccionista concebir el estrellato como un mero flirteo entre la cultura popular de masas, el consumismo y los rituales gregarios de las religiones. A fin de examinar su impacto en nuestras vidas cotidianas, deberíamos considerar el estrellato como una mitología contemporánea donde “las celebridades son nuestros compañeros comunes; son una 'narrativa' clave en las intimidades que construimos y en las historias que contamos y compartimos. Contamos la historia del mundo a través de las celebridades" (Marshall \& Redmond, 2015: 9).

En última instancia nos interesa observar cómo se originan luchas de clase, raza y sexo alrededor de un fenómeno tan conspicuo como es la cultura celebrity. Según Foucault (1976/1995: 116), el poder y sus dispositivos de regulación producen la 
norma hegemónica $\mathrm{y}$, de forma inherente, los mismos espacios de resistencia que son tratados de excluir. Esto es, el régimen normativo nunca se halla totalmente libre de la posibilidad de subversión. ¿Podría la mitología mainstream de las estrellas y sus comunidades de fans reflejar algún tipo de estas contiendas? ¿Puede ser el estrellato un campo de batalla donde se gestan las dinámicas de poder, subversión y transformación que experimenta la comunidad en la era digital? Hacer política desde el campo socio-cultural, esto es, desde disciplinas como los movimientos de género, la política medioambiental o el estrellato, significa sacar a la política de su constreñida noción de "legislación" (Brough \& Shrestova, 2012: párrafo 3.4). Reflexionemos acerca de artistas como David Bowie en su experimentación performativa con diversos alter ego y roles de género; Sam Smith y la identificación con lo queer y la identidad sexualidad fluida; Lady Gaga con la Born This Way Foundation (BTWF) y su apoyo a las víctimas del VIH y del sida; la boyband surcoreana BTS y su denuncia contra la presión académica juvenil y el bullying, o el choque generacional entre tradición y modernidad que cataliza el álbum conceptual $E l$ mal querer de Rosalía. Todos estos ejemplos reflejan el tipo de actividad política que sucede en el seno de la esfera cultural y artística, la realidad mediática y las comunidades virtuales; contiendas que abarcan desde el nivel micro del individuo hasta el nivel macro de los colectivos sociales.

\section{4. ¿Para qué las estrellas? El estrellato como mito- logía y religión en la era digital}

La concepción del pop como religión secular (Till, 2010) supone una ruptura respecto a ciertas narraciones y discursos de la modernidad tales como la distinción entre "alta cultura y baja cultura" (Abruzzese, 2004: 190), entre "cultura de élite y cultura comercial o de masas" (Jameson, 1991: 4) o entre "cultura sagrada y secular" (Till, 2010: 1). Con la "muerte de Dios" en la era posnietzscheana asistimos a una transformación de los referentes espirituales occidentales. Las figuras heroicas y divinas que representan comportamientos ideales son suplantadas por las estrellas de la cultura mainstream. Estas nuevas divinidades, además de representar una dimensión de lo ideal, integran comportamientos humanos y propios de la sociedad burguesa (Dyer, 1998: 22). Esta suerte de mitología de personajes excelsos y héroes, con sus sombras y sus luces, encarna los objetos de deseo, miedos, juicios y cosmovisiones profundamente arraigados en la cultura que los proyecta. 
El estrellato como mitología de la era digital: hiperculturalidad y El mal querer de... | 398

A fin de que se dé el proceso de encumbramiento de una figura, no solo es necesario cierto posicionamiento dentro de una jerarquía de talento (Rosen, 1981), sino también un proceso de idolatría o reconocimiento colectivo por "mímesis": a fin de invertir su necesidad de capital de consumo, los individuos emulan los hábitos de escucha de sus congéneres, lo que provoca la concentración de atención mediática sobre unas figuras y no sobre otras (Adler, 2006). Mediante la jerarquía de talento y la inversión colectiva de capital de consumo se construye una suerte de mitología contemporánea y mediática de celebrities. Esto abre un espacio de pertenencia y reconocimiento donde los ídolos ofrecen valores morales, rituales, narrativas y directrices morales que compiten con instituciones clásicas como la familia o la religión (Rojek, 2001: 97).

Al igual que los chamanes o los sacerdotes, los artistas son considerados seres con cualidades extraordinarias capaces de transgredir las normas de lo cotidiano y acercarnos a experiencias extáticas y trascendentes a través de ceremonias y ritos (Rojek, 2001). En palabras de Edgar Morin (1972: 23): “Elevadas a la categoría de héroes y divinizadas, las estrellas son algo más que objetos de admiración. Son también objetos de culto. Alrededor suyo se constituye una religión embrionaria". La notoriedad que estos personajes públicos alcanzan tan solo se ve acrecentada por el ecosistema digital y la actividad de los públicos conectados. La idolatría efervescente, el poder de convocatoria masivo o los billones de visitas a los videoclips que logran artistas como Bruno Mars, Ed Sheeran o Dua Lipa puede equipararse con la autoridad carismática (Weber, 1922/2002) ejercida por líderes espirituales como Gandhi, Buda Gautama o la figura religiosa del Papa. Sucesos como la muerte de David Bowie o Amy Winehouse encumbran a estos personajes al parnaso de la mitología contemporánea, desde donde, parafraseando a los Beatles, podríamos afirmar con certeza que los popstars son más conocidos que el propio Jesús.

De tal forma, los paralelismos entre religión, música popular y estrellato son notorios: la correspondencia entre la nave de las iglesias y las salas de conciertos - con la colocación de las estrellas (a modo de mediums entre lo divino y terrenal) en los altares-, el sentido de la congregación y la catarsis colectiva, la simbología compartida entre los grupos de fans y acólitos, el sentimiento de grandeza, el acto de "confesión" que realiza un individuo en íntima conexión con el artista, la 


\section{INNOVACIÓN TEÓRICA}

importancia de las grandes narraciones históricas, el atractivo sensorial, el valor de las reliquias y los autógrafos, los artefactos religiosos y la subasta de objetos de celebrities, o las ofrendas a los difuntos y la visita a la tumba de los famosos y a las catedrales que acogen los sarcófagos de santos. En última instancia, todos estos aspectos pertenecen a la esfera de lo ritual-simbólico y, como observa Byung Chul-Han (2020: 11), funcionan como "un signo de reconocimiento o una 'contraseña' entre gente hospitalaria (tessera hospitalis)".

Henry Jenkins (1992/2010: 24) señala cómo la palabra fan —abreviación de "fanático" en castellano y "fanaticus" en latín - procede del término latín "fanus", que significa "de o perteneciente al templo, un servidor del templo, un devoto". Este tipo de semejanzas evidencian cómo el estrellato, junto a otros movimientos colectivos como el activismo medioambiental, el deporte o la política, emula el papel integrador, la efervescencia colectiva y la sensación de comunión que ofrecen las religiones. Si tenemos en cuenta que "la palabra 'symbolon' pertenece al mismo campo semántico que 'relación', 'totalidad' y 'salvación'"' (Han, 2020: 16), examinaremos cómo en todas estas esferas posreligiosas de carácter secular la práctica de lo simbólico y los rituales funcionan igualmente engendrando "una alianza, una totalidad, una comunidad" (Han, 2020: 17). Si Durkheim (1912/2017) afirmó que el auge de la moral individualista estaba destinado a reducir la importancia de la religión, en este artículo llamamos a considerar de nuevo la importancia del "symbolon" como herramienta cohesionadora de subjetividades. Observamos cómo las comunidades digitales suponen una alternativa gregaria al bucle autorreferencial y narcisista descrito por las lecturas apocalípticas de la tecnocultura contemporánea (Baudrillard, 1970/2009; Lipovestky, 1983/2000; Eco, 1984; Han, 2018, 2020).

\section{El mal querer de Rosalía y la transformación de las identidades culturales contemporáneas}

El universo estético-musical generado por la artista catalana constituye una suerte de mitología propia de nuestro país. Con El mal querer, su segundo álbum de estudio, Rosalía y su equipo han generado una narrativa transmedia (Jenkins, 2006) sobre la violencia de género, el maltrato machista y el amor tóxico. Esta narrativa se despliega a través de once canciones, cinco videoclips, el diseño ar- 
El estrellato como mitología de la era digital: hiperculturalidad y El mal querer de... $\mid 400$

INNOVACIÓN TEÓRICA

tístico del álbum, destellos biográficos de la propia autora, stories de Instagram de la cuenta@rosalia.vt y el contenido generado por fans en diversas plataformas online que analizan dicho trabajo ${ }^{3}$. Además, este universo conceptual mantiene un diálogo intertextual con la novela occitana anónima El román de Flamenca (1287).

Tras la publicación de El mal querer el 2 de noviembre de 2018 se hizo patente la vertiginosa popularidad de Rosalía a través de varios hitos culturales: su cameo en el filme Dolor y gloria (2019) de Pedro Almodóvar, su interpretación de "Me quedo contigo" en los premios Goya de 2019, el marketing de El mal querer en la plaza Times Square o la mención del single "Malamente" en el puesto 23 de la lista The 200 best songs of the 2010s de la consagrada revista especializada Pitchfork. No hay duda de que la artista catalana ha generado símbolos que asociamos a un personaje bien demarcado en nuestro imaginario colectivo: desde el leitmotiv intergeneracional, el "trá trá" del estribillo de su single "Malamente", pasando por el retrato faceless de Rosalía creado por la popular artista Coco Dávez o el estilismo camp de las largas uñas de gel de sus videoclips. Constituidos como aquél "signo de reconocimiento o 'contraseña' entre gente hospitalaria (tessera hospitalis)" (Han, 2020: 11), todos estos símbolos compartidos de alcance internacional nos hablan de la autoridad carismática lograda por la artista catalana en el territorio nacional $\mathrm{y}$ allende sus fronteras.

A este respecto, Max Weber (1922/2002: 172-173) nos habla de la autoridad carismática - alternativa a la dominación tradicional y burocrática- como un tipo de dominación de orígenes religiosos donde un individuo singular o heroico es encumbrado basándose en unas cualidades personales y extraordinarias. En el caso del estrellato, Richard Dyer (1998: 18) afirma que "ese atractivo carismático es efectivo especialmente cuando el orden social es incierto, inestable y ambiguo y cuando la figura carismática o grupo ofrece un valor, orden o estabilidad para contrarrestar esto". En el caso del fenómeno Rosalía, observamos cómo la narrativa de $E l$ mal querer -el maltrato y el posterior renacimiento heroico de Flamenca, la protagonista femenina sometida a una relación posesiva-, la fusión sonora entre la tradición flamenca y la electrónica experimental, y la estética camp de los videoclips producidos por la compañía Canadá catalizan problemáticas sociales en boga: la violencia machista, la agenda política de los movimientos de género LGT- 


\section{INNOVACIÓN TEÓRICA}

$B I Q+$ y la búsqueda de paridad social en la industria musical, cuestiones agrupadas bajo el paraguas de la cuarta ola feminista (Sternadori, 2019); los debates sobre la apropiación cultural, los fundamentalismos del lugar y la diferenciación étnica en la era global (McLaren, 1997; Hall, 2003; Steingress, 2005; Mbembe, 2016; Han, 2018); o el choque generacional entre el zeitgeist de la cultura millennial digitalizada, el trap, el uso de samplers y la música popular urbana con aspectos tradicionales como la tauromaquia, la copla, el idioma caló, el acervo flamenco o el imaginario nacionalista.

La propagación global de todas las características anteriormente descritas a través de la red es sintomática de cómo el fenómeno Rosalía refleja la noción de hiperculturalidad descrita por Byung-Chul Han (2018). Si Zygmunt Bauman nos habla acerca de "la volatilidad de las identidades" en la modernidad líquida (Bauman, 2002: 188), es necesario contemplar un espacio que igualmente pierda sus características sólidas a fin de favorecer el flujo de datos y el intercambio de identidades. Han (2018) nos habla precisamente de la hiperculturalidad como ese estado, asistido por el espacio virtual, en donde "todas las relaciones son equidistantemente próximas" (Núñez Ladevéze \& Irisarri, 2015: 482) y donde la facticidad de la cultura es eliminada -esto es, su pertenencia fundamentalista a un punto geográfico y su fijación rígida dentro de unas fronteras definidas, un espacio y un tiempo-. Este desplazamiento de la cultura de su espacio "original" la disuelve en un universo hipertextual: la posibilidad de acceso a infinidad de fenómenos yuxtapuestos, no ordenados de una manera secuencial o jerárquica, abre los horizontes del usuario al "hiperespacio de posibilidades", el eclecticismo constituyente de la hiperculturalidad (Han, 2018: 18).

La tecnología digital interactiva e internet, entendido este último como un espacio de comunicación más que como un medio (Llorca, 2005), son los factores que en mayor medida han favorecido la hiperculturalidad y la volatilización de las percepciones tradicionales del espacio-tiempo. Muestra de ello son las posibilidades que abre el ordenador como metainstrumento que controla todas las fases de la producción (Márquez, 2010), o la libertad sin precedentes que logran los artistas a la hora de acceder a audiencias globales a través del entorno digital, (Loy et al., 2018: 11). Medios como YouTube, Spotify, Google Analytics e Instagram, o 
El estrellato como mitología de la era digital: hiperculturalidad y El mal querer de... | 402

INNOVACIÓN TEÓRICA

programas de edición/creación como AutoCAD, Photoshop, Logic-Pro y Sony Vegas son un pequeño ejemplo de la infinita panoplia de herramientas que inaugura "el hiperespacio de posibilidades" digital (Han, 2018: 18).

Este contexto es, precisamente, el que ha permitido que la difusión y notoriedad de la música popular y los artistas no haya dejado de crecer. Según el VEVO Music Fan Report: The Millennial Fan Tribes (2015), la música se posiciona como la categoría de entretenimiento más compartida en redes sociales (superando a las celebrities sociales, los deportes, la televisión o las películas). En comparación con los influencers o las celebrities de Hollywood, las estrellas musicales se alzan como los referentes más deseados, ostentando la mayor cantidad de talento percibido según el 51\% de los encuestados (VEV0, 2015). En la concepción de la identidad como proceso que media entre nuestra subjetividad y el grupo (la paridad "yo-nosotros"), la música se presta como una potente herramienta que permite "generar identidades culturales compartidas a través del discurso sonoro" (Hormigos, 2010: 97). Dado que la articulación de la identidad necesita de referentes para constituirse, la música ofrece una experiencia estética y somática directa que integra al individuo dentro de un paisaje cultural intersubjetivo (Firth, 2003), mientras que las estrellas actúan como vectores o tótems que aglutinan dichas prácticas comunitarias alrededor de sus personalidades notorias.

De este modo, la rápida extensión global de un fenómeno tan idiosincrático como es el universo Rosalía es sintomático de la hipercultura digitalizada y las transformaciones a las que asisten las identidades contemporáneas:

1. Los individuos trascienden las etiquetas sociales prefijadas: la generación millennial muestra la tendencia a una menor identificación con tribus musicales $^{4}$ a favor de un eclecticismo sin precedentes (Spotify, 2018). No es solo el gusto, sino las prácticas y formas de fruición alrededor de los bienes culturales y estéticos que ahora determinan la configuración de las identidades en el hiperespacio de posibilidades (Hennion, 2010).

2. En las prácticas de constitución de las minorías y colectivos generacionales, los fenómenos macro han sido desplazados por una miríada de esferas micro que guardan un carácter mucho más íntimo y ligado a experiencias personales 


\section{INNOVACIÓN TEÓRICA}

y al consumo de lo "estético-cultural" (Luchetti, 2009: 8): “Unas sociedades que se identifican cada vez más con eventos culturales, antes que políticos, ponen en escena de modo bastante certero la efectividad de las industrias culturales en la configuración identitaria" (Luchetti, 2009: 8).

3. Como hemos dicho, internet inaugura un modelo de cultura no fundamentalista: esta es liberada de su emplazamiento "original" y sus límites espaciotemporales. Lo local es atravesado por el espacio digital y por las dinámicas de consumo globales, lo que nos conduce a una concepción de la identidad cultural más fluida. Esta tensión entre lo local y lo global —conocida como glocalización - tiene como consecuencia el ensalzamiento del "poder de las identidades" en la era de la "sociedad red" (Castells, 1997: 163), donde "la reafirmación identitaria de los colectivos humanos, la localización" (Martí, 2000: 55), se vuelve una reacción contra la pérdida de la alteridad provocada por la yuxtaposición hipercultural (Han, 2018; 2020).

Retomando la noción de la acción política ejercida desde la esfera cultural y el estrellato, el fenómeno Rosalía refleja el interés de los colectivos LGTBIQ+ y la paridad social, pone sobre la mesa los actuales debates sobre apropiación cultural, y refleja el encuentro entre modernidad y tradición: “La identidad cultural supone una mediación incesante entre tradición y renovación, permanencia y transformación, emoción y conocimiento" (Hormigos, 2010: 94).

\section{Conclusiones}

En su función de receptáculos semiótico-culturales y somático-emocionales, las estrellas constituyen el reflejo de la civilización que las engendra. Encumbradas al protagonismo mediático, estas se encargan de suplir la necesidad afectivo-mítica del público. Mediante la canalización común del capital de consumo y la práctica de investir a ciertos individuos de autoridad carismática generamos un parnaso de personajes excelsos que proyectan nuestros valores, miedos y deseos colectivos. De esta forma, los paralelismos entre cultura celebrity y religión nos lleva a considerar la transformación de las comunidades de fans en la era digital, donde el estrellato se establece como mitología moderna y secular que nos permite ahondar en la comprensión de nosotros mismos como colectivo. 
El estrellato como mitología de la era digital: hiperculturalidad y El mal querer de... | 404

Si Byung-Chul Han señala que "el mundo sufre hoy una fuerte carestía de lo simbólico" (Han, 2020: 12) y que "la crisis actual de la comunidad es una crisis de resonancia" (Han, 2020: 23), este artículo concluye que el espacio digital interconectado permite una transformación más activa y comprometida de las audiencias. Los fans, al mantener una comunicación más directa y bidireccional con sus ídolos, se acercan a la concepción de los "públicos conectados" (Ito, 2008). La interacción digital comunitaria junto a las luchas de raza, sexo y clase situadas en interseccionalidad con el estrellato suponen un lugar fecundo para la práctica gregaria del "symbolon" (lo simbólico) y los rituales posreligiosos.

Partiendo del carácter polimórfico del estrellato, concebimos el fenómeno Rosalía como un ejemplo paradigmático de campo de batalla cultural desde donde ejercer la acción política - desde donde subvertir los efectos tóxicos del pharmakon-. Es alrededor de El mal querer que reviven los debates sobre la apropiación cultural y la diferenciación étnica en la era global e hiperconectada, además de ser catalizadas problemáticas sociales en boga como la lucha por la igualdad de género, la agenda de los movimientos LGTBIQ+ o la colisión entre el imaginario millennial y la cultura tradicional española. En última instancia, estas contiendas reflejan la transformación que experimenta la tradición, la concepción no fundamentalista de la cultura y el papel activo de las audiencias en la configuración de las identidades culturales contemporáneas.

\section{Fuentes de financiación}

Este artículo forma parte del proyecto "Nuevos escenarios de vulnerabilidad digital: alfabetización mediática para una sociedad inclusiva" (PROVULDIG-2), financiado por la Comunidad de Madrid y el Fondo Social Europeo (ref. H2019/HUM-5775).

\section{Referencias}

Abruzzese, A. (2004). “Cultura de masas". CIC, 189-192. Recuperado de $<$ https:// bit.ly/3nTYTBT>.

Adler, M. (2006). "Stardom and talent". Handbook of the Economics of Art and Culture, 1, 895-906. <https://doi.org/10.1016/S1574-0676(06)01025-8> 
405 | Mateu Terrasa Rico, Ignacio Blanco Alfonso y Margarita Garbisu Buesa

INNOVACIÓN TEÓRICA

Andrea Sereni, C. (2021). "Digital nomos and the new world order: towards a theological critique of Silicon Valley". Tapuya: Latin American Science, Technology and Society, 4(1), 1843870. <https://doi.org/10.1080/25729861.2020.1843870>

Baudrillard, J. (2009). La sociedad de consumo. Sus mitos, sus estructuras. Madrid: Siglo XXI. Versión original de 1970. Recuperado de <https://bit.ly/3m0I35W>. Bauman, Z. (2002). Modernidad líquida. México: Fondo de Cultura Económica Española. Recuperado de <https://bit.ly/3n2F9e9>.

Brough, M. M. y Shresthova, S. (2012). "Fandom meets activism: rethinking civic and political participation". Transformative Works and Cultures, 10. <https://doi. org/10.3983/twc.2012.0303>

Busquet-Duran, J. (2012). "El fenómeno de los fans e ídolos mediáticos: evolución conceptual y génesis histórica". Revista de Estudios de Juventud, 96, 13-29. Recuperado de <https://bit.ly/2WSqI1j>.

Carrión, J. (Ed.). (2021). La Rosalía. Ensayos sobre el buen querer. Errata Naturae: Madrid. Recuperado de <https://amzn.to/3kZWtAL>.

Castells, M. (1997). El poder de la identidad, Vol. II. La era de la identidad. Economía, sociedad y cultura. Buenos Aires: Siglo Veintiuno Editores. Recuperado de <https:// bit.ly/340EOFj>.

Castro, E. (2019). El trap. filosofía millennial para la crisis en España. Errata Naturae: Madrid.

Click, M., Lee, H. y Holladay, H. (2015). “You're born to be brave: Lady Gaga's se of social media to inspire fans political awareness". International Journal of Cultural Studies, 20(6), 603-619. <https://doi.org/10.1177/1367877915595893 >

Debord, G. (1967). La société du spectacle. París: Buchet-Chastel. Recuperado de <https://bit.ly/3mQcDw9>.

Duffett, M. (2013).“ Introduction: Directions in Music Fan Research: Undiscovered Territories and Hard Problems", Popular Music and Society, 36(3), 299-304. <https://doi.org/10.1080/03007766.2013.798538>

Durkheim, E. (2017). Las formas elementales de la vida religiosa. Ciudad de México: Colofón. Versión original de 1912. Recuperado de <https://bit.ly/3hV5AkG>

Dyer, R. (1998). Stars. Londres: British Film Institute. Recuperado de <https://bit. ly/3rChpB4>.

Eagleton, T. (17 de noviembre de 2016). La endeblez del posestructuralismo. Revista de Libros. Recuperado de <https://bit.ly/39pyVRg>. 
El estrellato como mitología de la era digital: hiperculturalidad y El mal querer de... | 406

INNOVACIÓN TEÓRICA

Eco, U. (1984). Apocalípticos e integrados. Barcelona: Lumen. Recuperado de $<$ https://bit.ly/3ptHgcf>.

Findeisen, F. (2015). The addiction formula: A holistic approach to writing captivating, memorable hit songs. Enschede: Albino Publishing. Recuperado de $<$ https://bit.ly/38Fpo7E>.

Firth, S. (2003). "Música e identidad". En: S. HALL y P. D. GAY (Eds.), Cuestiones de identidad cultural, (pp. 181-213). Buenos Aires : Amorrortu. Recuperado de $<$ https://bit.ly/3ho7oCv>.

Fiske, J. (1989). Reading the popular. Londres: Routledge. Recuperado de <https:// bit.ly/370epJk>.

Foer, F. (2017). Un mundo sin ideas. La amenaza de las grandes empresas tecnológicas a nuestra identidad. Barcelona: Paidós. Recuperado de <https:// bit.ly/2Pc0A1u>.

Foucault, M. (1995). La voluntad de saber. Historia de la sexualidad 1. Madrid: Siglo XXI. Versión original de 1976. Recuperado de <https://bit.ly/3rJip6q>.

Hall. S. (2003). “¿Quién necesita identidad?” En: S. HALL y P. D. GAY (Eds.), Cuestiones de identidad cultural, (pp. 13-39). Buenos Aires: Amorrortu. Recuperado de <https://bit.ly/3ho7oCv>.

Han, B. C. (2018). Hiperculturalidad. Barcelona: Herder. Recuperado de <https:// bit.ly/2KFECBy>.

- (2020). La desaparición de los rituales. Barcelona: Herder. Recuperado de $<$ https://bit.ly/3nTxBeI>.

Hennion, A. (2010). “Gustos musicales: de una sociología de la mediación a una pragmática del gusto". Comunicar, 34, 25-33. <https/doi.org/10.3916/C34-2010-02-02>

Horkheimer, M. y Adorno, T. (1998). Dialéctica del iluminismo. Madrid: Editorial Trotta. Versión original de 1944. Recuperado de <https://bit.ly/3pGZmrF>.

Hormigos, J. (2010). “Distribución musical en la sociedad de consumo. La creación de identidades culturales a través del sonido". Comunicar, 34, 91-98.<https:// doi.org/10.3916/C34-2010-02-09>.

Illescas-Martínez, J. E. (2011). Las industrias culturales hegemónicas como generadoras de un nuevo concepto de "lo latino" en el sistema mundial: el caso del videoclip en la primera década del siglo XXI [trabajo de investigación de doctorado]. Universidad de Alicante, Alicante. Recuperado de <https://bit.ly/3rm3iz1>. 
- (2014). Industrias culturales y juventud en el sistema-mundo. El videoclip mainstream como mercancía y como reproductor de ideología [tesis doctoral, Universidad de Alicante]. Respositorio Institucional de la Universidad de Alicante. Recuperado de <https://bit.ly/301dbRi>.

Inglis, F. (2010). A short history of celebrity. Princeton: Princeton University Press. Recuperado de <https://bit.ly/3a0gGGP>.

Ito, M (2008). “Introduction”. En K. VARNELIS (Ed.), Networked publics (pp. 1-14). Boston: MIT Press. Recuperado de <https://bit.ly/38Dz8PP>.

Jameson, F. (1991). El posmodernismo o la lógica cultural del capitalismo avanzado. Barcelona: Paidós. Recuperado de <https://bit.ly/2WN7mea>.

Jenkins, H. (2006). Convergence culture: Where old and new media collide. Nueva York: New York University Press. Recuperado de <https://bit.ly/3mY2LQ0>.

- (2010). Piratas de textos. Fans, cultura participativa y televisión. Barcelona: Paidós. Versión original de 1992. Recuperado de <https://bit.ly/2WRRKWE>.

- (2012). "Cultural Acupuncture: Fan activism and the Harry Potter alliance". Popular Media Cultures, 206-229. Recuperado de <https://doi.org/10.3983/ twc.2012.0305>.

Jenkins, H. y Shresthova, S. (2012). “Up, up, and away! The power and potential of fan activism". Transformative Works and Cultures, 10. <https://doi. org/10.3983/twc.2012.0435>.

Jones, B. (2012). “Being of service: 'X-Files' fans and social engagement". Transformative Works and Cultures, 10. <https://doi.org/10.3983/twc.2012.0309>.

Lipovetsky, G. (2000). La era del vacío. Ensayos sobre el individualismo contemporáneo.

Barcelona: Anagrama. Versión original de 1983. Recuperado de <https://bit. ly/38Ilg6K>.

Loy, S., Rickwood, J., y Bennett, S. (2018). Popular music, stars and stardom. Australia: Australian National University Press. Recuperado de <https://bit. ly/3aS3As3>.

Luchetti, M.F. (2009). La alteridad como configuradora de la identidad [Conferencia]. V Jornadas de Jóvenes Investigadores, Buenos Aires, Argentina. Recuperado de $<$ https://bit.ly/3pvFYOA>.

Márquez, I. V. (2010). “Hipermúsica: la música en la era digital”. TRANS, 14 2010). Recuperado de <https://bit.ly/2JshjdW>. 
El estrellato como mitología de la era digital: hiperculturalidad y El mal querer de... $\mid 408$

Marshall, P. D. (2010). "The promotion and presentation of the self: Celebrity as marker of presentational media". Celebrity Studies, 1(1), 35-48. <https:// doi.org/10.1080/19392390903519057>.

Marshall, P. D. y Redmond, S. (2015). "Introduction". En: P. D. MARSHALL y S. REDMOND (Eds.), A Companion to Celebrity (pp. 1-14). Sussex: John Wiley \& Sons. Recuperado de <https://bit.ly/2KF0J9u>.

Martí, J. (2000). Más allá del arte. La música como generadora de realidades sociales. San Cugat del Vallès, Barcelona: Deriva Editorial. Recuperado de <https://bit. ly/3rwNJFf>.

Mbembe, A. (2016). Crítica de la razón negra. Ensayo sobre racismo contemporáneo. Barcelona: Futuro Anterior Ediciones. Recuperado de <https://bit.ly/3rARVDS>. Mclaren, P. (1997). Pedagogía crítica y cultura depredadora. Políticas de oposición en la era posmoderna. Barcelona: Paidós educador. Recuperado de < https:// bit.ly/2KVj43D>.

Meyer, P. (Ed.) (2018). Le roman de Flamenca [El román de Flamenca]. Aberdeen, Inglaterra: Wentworth Press. Versión original de 1287. Recuperado de <https:// amzn.to/2WSDvB8>.

Morin, E. (1972). Las stars. Servidumbres y mitos. Barcelona: Dopesa. Recuperado de <https://bit.ly/38D7p1K>.

Núñez-Ladevéze, L. e Irisarri, J. A. (2015). “Industria cultural y relaciones 'cara a cara' en las redes: la continuidad del cambio en España". Estudios sobre el Mensaje Periodístico, 21(1), 471-490. <https://doi.org/10.5209/rev ESMP.2015.v21.n1.49106>.

Redmond, S. (2015). "Part six. Emotional celebrity". En P. D. MARSHALL y S. REDMOND (Eds.), A Companion to Celebrity (pp. 351-354). Sussex: John Wiley \& Sons. Recuperado de <https://bit.ly/38JEw3E>.

Rheingold, H. (1996). La comunidad virtual: una sociedad sin fronteras. Barcelona: Gedisa. Recuperado de <https://bit.ly/3nZN7Ww>.

Rojek, C. (2001). Celebrity. Londres: Reaktion Books. Recuperado de <https://bit. ly/3pqINzZ>.

Rolnik, S. y Guattari, F. (2006). Micropolíticas. Cartografias del deseo. Madrid: Traficantes de Sueños. Recuperado de <https://bit.ly/3w8Wh7A >.

Rosen, S. (1981). "The economics of superstars". The American Economic Review, 71(5), 845-858. Recuperado de <https://bit.ly/3nUoryx>. 


\section{INNOVACIÓN TEÓRICA}

Rouvroy, A. y Berns, T. (2018). “Gobernabilidad algorítmica y perspectivas de emancipación: ¿lo dispar como condición de individuación mediante la relación?". Ecuador Debate, 104, 124-147. Recuperado de <https://bit.ly/3sHbCKE>.

Sadin, E. 2018. La silicolonización del mundo. La irresistible expansión del liberalismo digital. Buenos Aires: Caja Negra Editora. Recuperado de <https:// bit.ly/20SZyYA>

Siles-González, I. (2005). "Internet, virtualidad y comunidad". Revista Ciencias Sociales, 108, 55-69. Recuperado de <https://bit.ly/2WTg7m0>.

Spotify, (2018). Spotify for Brands Understanding People Through Music: Millennial Edition. Recuperado de <https://bit.ly/3nPVgNe>.

Steingress, G. (2005). “La hibridación transcultural como clave de la formación del nuevo flamenco (aspectos históricos-sociológicos, analíticos y comparativos)". Música Oral del Sur, 119-152. Recuperado de <https://bit.ly/3pAa03n>.

Sternadori, M. (2019). "Situating the fourth wave of feminism in popular media discourses". En: M. B. MARRON (Ed.), Misogyny and Media in the Age of Trump (pp. 31-55). Washington: Lexington Books. Stiegler, B. (2015). La société automatique I. L'avenir du travail. París: Fayard.Recuperado de <https://bit. ly/31wzNzj>.

Terrasa Rico, M. (2021). “El framing y la construcción de estrellato en la era digital. Estudio de caso: El mal querer de Rosalía en la prensa escrita española (2018-2020)". Doxa Comunicación, 32, pp. 381-404. Recuperado de <https:// doi.org/10.31921/doxacom.n32a18>.

Till, R. (2010). “The Personality Cult of Prince: Purple Rain, Sex and the Sacred, and the Implicit Religion Surrounding a Popular Icon". Implicit Religion, 13(2), 141-159. Recuperado de <https://bit.ly/38F2gGr>.

Turner, G. (2014). Understanding celebrity. Londres: SAGE. <http://doi. org $/ 10.4135 / 9781473957855>$.

Vera, A. (2020). El pharmakon artístico. En R. Filinich y S. Toro (Presidencia), De la farmacología a la organología. Diálogos en torno al pensamiento de Bernard Stiegler. Congreso llevado a cabo en Universidad de Valparaíso, Chile. Recuperado de <https://bit.ly/3czSwQG>.

VEV0, (2015). VEV0 Music Fan Report: The Millennial Fan Tribes. Recuperado de $<$ https://bit.ly/3hia3ha>. 
El estrellato como mitología de la era digital: hiperculturalidad y El mal querer de... $\mid 410$

INNOVACIÓN TEÓRICA

Weber, M. (2002). Economía y sociedad. Esbozo de sociología comprensiva. Madrid: Fondo de cultura económica. Versión original de 1922. Recuperado de <https:// bit.ly/3n2Yhst>.

Wohlfeil, M., Patterson, A. y Gould, S. J. (2019). "The allure of celebrities: Unpacking their polysemic consumer appeal". European Journal of Marketing, 53(10), 2025-2053. <https://doi.org/10.1108/EJM-01-2017-0052>.

\section{Notas}

[1] La conceptualización de pharmakon de Stiengler nos lleva a una dimensión radicalmente económica y política del concepto utilizado por Derrida y por Platón en El Fedro. De tal forma, pharmakon se equipara a técnica en cuanto prolongación exosomática de las facultades psicofisiológicas y exteriorización de la propia memoria humana. Haciendo una referencia directa a Nietzsche, Stiengler traza una genealogía exosomática de la moral, a partir de la cuál observa cómo la condiciones materiales o técnicas de cada época determinan el humus de valores compartidos y la psique colectiva de cada sociedad. La incorporación de lo artificial o técnico dentro de la evolución cultural del hombre sienta las bases de su teoría organológica y del malestar algorítmico contemporánea (la relación tóxica entre órganos psicosomáticos, órganos artificiales e instituciones sociales). Determinando cómo los efectos tóxicos del pharmakon y del capitalismo tecnológico tienen su reflejo en el malestar contemporáneo y el nihilismo propio del Antropoceno. Véase La société automatique I. L'avenir du travail (2015) del mismo autor.

[2] Información acerca de Rosalía como personalidad más buscada de 2018 extraída de Google Trends: https://trends.google.es/trends/yis/2018/ES/

[3] Véase el análisis de la música y el marketing de El mal querer realizado por Jaime Altozano y Neus Díez, respectivamente, en la plataforma YouTube.

[4] En la era streaming, la pertenencia a una tribu ya no se define únicamente por el género musical (el eclecticismo y búsqueda constante de novedad son hábitos propios de las audiencias jóvenes) (VEV0, 2015), sino también por los patrones y modos de consumo. Proponiendo, en el caso del informe de VEVO (2015) cuatro perfiles de tribu musical: el caza-talentos (A), el fan de la primera fila (B), el surfista de multitudes (C) y el solista (D).

\section{(a) (1)}

Este obra está bajo una licencia de Creative Commons Reconocimiento 4.0 Internacional.

DOI: ri14.v19i2.1734| ISSN: 1697-8293 | Julio - diciembre 2021 Volumen 19 NN$^{\circ} 2$ | ICONO14 